\title{
Analysis of Teacher Beliefs and Efficacy for Teaching Writing to Weak Learners
}

\author{
Tunku Mohani Tunku Mohtar ${ }^{1}$, Charanjit Kaur Swaran Singh ${ }^{1}$, Napisah Kepol ${ }^{1}$, Ahmad Zainuri Loap Ahmad ${ }^{1}$ \& \\ Sasigaran Moneyam ${ }^{2}$ \\ ${ }^{1}$ English Language and Literature Department, Faculty of Languages and CommunicationUniversiti Pendidikan, \\ Sultan Idris, 35900 Tanjong Malim, Perak, Malaysia \\ ${ }^{2}$ Centre for Languages and General Studies, Universiti Pendidikan Sultan Idris, 35900 Tanjong Malim, Perak, \\ Malaysia
}

Correspondence: Charanjit Kaur Swaran Singh, English Language and Literature Department, Faculty of Languages and CommunicationUniversiti Pendidikan Sultan Idris, 35900 Tanjong Malim, Perak, Malaysia. Tel: 60-054-505-000. E-mail: charanjit@ffbk.upsi.edu.my

Received: July 2, 2017 Accepted: August 18, 2017 Online Published: August 21, 2017

doi: 10.5539/elt.v10n9p208ＵRL: http://doi.org/10.5539/elt.v10n9p208

\begin{abstract}
The present study investigated the beliefs and efficacy of a teacher teaching English to students who were weak at the language. The objective of the study was mainly to investigate the beliefs and efficacy of the ESL teacher for teaching writing to weak learners. The research was a case study of the English Language teacher teaching Form Three class of students whose English proficiency was very low. An interview was conducted with the teacher to further probe the instructional strategies applied to enhance her beliefs and efficacy in her own capabilities to make learning happen in her classroom. Observations were made to investigate the teacher's efficacy in teaching and the performance of the students specifically for writing. Results show the teacher's beliefs of her students' capabilities and their language needs helped shape the teacher's instructional strategies. The teacher's efficacy enabled her to decide to undertake the task of teaching writing to her students because she was confident in her ability. The teacher provided clues to the students to facilitate their learning. This kind of feedback from the teacher indirectly motivated them to learn. The teacher's beliefs and efficacy contributed to her teaching practice and the instructional strategies that she used in turn enhanced her beliefs and efficacy. The study implicates that teacher's beliefs and efficacy can assist the weak learners in improving their writing skills and also facilitate language learning.
\end{abstract}

Keywords: teacher beliefs, teacher efficacy, ESL teachers, instructional strategies, weak ESL learners

\section{Introduction}

English is a global language by virtue of its influence on the Internet as well as various forms of media. As technology keeps on developing, communication with foreign nations becomes easy and necessary. According to Crystal (1997, p. 2) "a language achieves a genuinely global status when it develops a special role that it is recognised in every country". In terms of education, English is now 'the most widely taught foreign language in the world' (Crystal, 2003, p. 5). It has become a global academic language in view of globalisation of higher education. Universities are now competing at a global level and the role of higher education is putting pressure on the rest of the education system. Hence, there is a need for it to be taught in schools to prepare students to pursue studies a university level and if not, to equip them with a certain degree of English proficiency to enable them to access information that is available in English. Malaysia requires a workforce that is competent in English in order to sustain itself in a competitive world market. As a result, the influence of the English language on speakers who learn it as a second or foreign language in Malaysia has left a lot to be desired. This is especially so in areas where exposure to English is very minimal. English is only used in the classroom during the English language lessons. Teachers and students do not communicate in English outside the classroom. In some English Language classes the teachers had to resort to using the students' mother tongue or the Malay language, which is the main medium of instruction now. The lack of suitable reading materials and resources for students and teachers poses a great challenge to the ESL teachers. The teachers have to work with limited resources to combat the poor performance of their students in the English Language examinations. 


\subsection{Background of the Study}

The decline in English language competency of Malaysian students was a great concern among leading figures of the government as well as the private sector. It was feared that the phenomenon could affect the country's journey towards industrialisation. This state of affairs led to the teaching of Science and Mathematics in English. The move started in 2003 when English was reintroduced as the medium of instruction but only for Science and Mathematics at Primary One, Secondary One and Lower Six Secondary level. By 2009, English would be used as the medium of instruction for Science and Mathematics at all levels in secondary schools. The problem of mastering the English language does not involve students alone. The English language teachers are also affected. When students lack of English foundation background, they will exhibit lack of confidence to use English because they are afraid of making mistakes. Thus teachers will also face difficulties teaching English language to students who are not well-motivated and geared towards learning. Ineffective teaching leads to ineffective learning. There are teachers who have not been trained to teach the language yet are teaching it because of the lack of trained teachers in the rural areas. English language proficiency among students as well as teachers in the rural areas is very low. Students in rural schools generally find it difficult to maintain their interest in English language learning as English is not seen as important for their immediate need. Teachers on their part are unable to sustain learners' genuine interest in continuing to learn English and to use the language once the examination is over.

This is evident from a complaint by a parent who claimed that the Science and Mathematics teachers had been using Bahasa Malaysia ( Malay Language) to teach these subjects when they should be using English (Teacher flouting rules, 8 February 2009). Hence many students perform poorly in the English Language Paper in national examinations. Teaching English as a second language to beginners is full of challenges (Tunku Mohani Tunku Mohtar et al., 2015). What is more challenging is teaching the language to very young learners whose command of the first language is still very tender. A more daunting task is to enable them to use the language orally and also in writing (Tunku Mohani Tunku Mohtar et al., 2015). One way of helping weak learners improve their language proficiency is to provide assistance to the teachers teaching them. In order to do that an analysis of the teachers' beliefs on their efficacy in teaching will need to be conducted to establish the type of assistance they require. Teaching is a cognitive activity and hence the teachers' beliefs greatly influence their decision regarding their instructional practices (Tillema, 2000). "A teacher's efficacy belief is a judgment of his or her capabilities to bring about desired outcomes of student engagement and learning, even among those students who may be difficult or unmotivated" (Tschannen-Moran \& Hoy, 2001, p. 783). If they believe that they can motivate their students to learn, then they will be able to do it. According to Kurz et al. (2007, p. 21), "optimism can be learned and developed". Only then can assistance in terms of teaching modules and training be planned and developed". The fundamental study of teacher efficacy was initiated by the Rand foundation (1976 and 1977). In this study the sense of teacher self-efficacy was positively related to student achievement (Denham \& Michael, 1981). The purpose of this paper was to explore the teacher's beliefs and efficacy regarding her pedagogical practices and to discover the extent to which her beliefs influence her pedagogical practices.

\subsection{Research Objectives}

This study intended mainly to discover how the teacher's belief and efficacy affected her instructional practices and hence her students' performance in the English Language classroom. The teacher's beliefs in her own teaching competence and in her students' capabilities would influence her teaching. The objectives of the study could thus be summarised as follows:

To investigate the beliefs and efficacy of the ESL teacher

For the purpose of this study, only the writing skill was investigated. This skill was focused on writing as an integrative skill. Other skills such as reading, listening and speaking are integrated within the writing skill. Students would be required to write sentences and compositions. In the course of writing they would need to read what they wrote. Furthermore, texts which provided information for students to use for writing required them to read. They would also need to listen to the teacher's explanations and to ask for information where required. Teachers' sense of efficacy has the potential to influence both the kind of environment that they produce as well as the various instructional practices introduced in the classroom (Bandura, 1997). Moreover, teachers with a high sense of self-efficacy are confident that even the most difficult students can be reached if they exert extra effort; teachers with lower self-efficacy, on the other hand, feel a sense of helplessness when it comes to dealing with difficult and unmotivated students (Gibson \& Dembo, 1984).

\subsection{Research Question}

What are the teacher's beliefs about her own teaching? 
In the field of ESL/EFL, the importance of exploring how the language teachers' thoughts, judgments, and decisions influence the nature of language teaching has begun to be recognised (Borg, 2003). Drawing on the ideas related to teacher beliefs, this study explored the ESL/EFL teacher's classroom practices to examine how the language teacher made instructional decisions, use teaching materials and teaching techniques.

\section{Literature Review}

Teachers' beliefs are not easy to define or study as they are not directly observable (Johnson, 1994). However, an investigation of teachers' beliefs can provide significant insights into many aspects of teaching.

\subsection{Teacher Belief}

The word "belief" is defined in a variety of ways. Among the definitions Pajares (1992) claims are attitudes, values, judgment, axioms, opinions, ideology, perceptions, conceptions, preconceptions, dispositions, personal theories, implicit theories, explicit theories and practical principles. Richards (1998) defines belief as 'the information attitudes, values, expectations, theories, and assumptions about teaching and learning that teachers build up over time and bring with them to the classroom' (p. 66). Beliefs play a major role in influencing the way a teacher teaches. Believes are personal constructs which can provide insights into a teacher's practice (Pajares, 1992). Research has shown that the teachers' beliefs are related to their teaching (Tillema, 2000). According to Pajares (1992), teachers tend to rely more on their belief than on research-based theories. Klein opines that "anyone who claims that second language instruction must be arranged in a particular way on the evidence available from linguistics or neurophysiology or any other science, displays a fair amount of naivety if not assumption" (O’Neill, 1999).

Nespor (1987) considers teachers' beliefs as their personal pedagogies or theories. The environments and contexts they work in are rather complex and changes fairly often that they use their beliefs to make sense of such contexts. Teachers are often given different sets of students each year to teach. They are also subject to transfers that they may not remain long in one school. Hence their teaching environments are neither fixed nor stable. At one point in time they may be teaching good and active learners and another time very weak and passive learners. In the field of second language education, teaching is complex cognitive activity (Borg, 2003). In their study, Shavelson and Stern found that what the teachers did in the classroom was influenced by their beliefs. Borg (2003) suggests that "teachers are active, thinking decision-makers who make instructional choices by drawing on complex practically-oriented, personalised, and context-sensitive networks of knowledge, thought, and beliefs" (p. 81). Their teaching experiences, classroom practices, and their personalities contribute in the shaping of their beliefs (Borg, 2003). Research has shown that teachers have a wide range of beliefs about pedagogical issues such students and teaching (Borg, 2003; Farrell \& Lim, 2005; Burns, 1992; Shavelson \& Stern, 1981).

\subsubsection{Teacher Efficacy}

A teacher's efficacy refers to "the extent the teacher believes he or she has the capacity to affect student performance" (Berman et al., 1977, p. 137), his or her belief in his or her capability to organise and execute courses of action to successfully accomplish a specific teaching task in a particular context, the belief that he or she "can influence how well students learn, even those who may be difficult or unmotivated" (Guskey \& Passaro, 1994, p. 4), the teacher's belief that he or she is able to bring about student engagement and learning outcomes, even when the students are challenging. In the field of English as a second language, a teacher whose belief in his or her teaching or English language competence is not strong enough will not be able to promote learning among the learners. Teachers with high efficacy are more likely to experiment with methods of instruction, seek improved teaching methods, and experiment with instructional materials (Pajares, 1992).

A number of previous studies have elaborated about the influence of teacher self-efficacy beliefs on student's achievement and success at school (Muijs \& Rejnolds, 2001; Tournaki \& Podell, 2005).

Ross (1992) investigated the relationship between student achievement, teacher efficacy, an interaction with assigned coaches on a sample of 18 grade 7 and 8 history teachers in 36 classes. The result of the study indicated that students' achievement was higher in classrooms of teachers who had more contact with their coaches, and in classrooms of teachers with greater confidence in the effectiveness of education.

In addition, Tournaki and Podell (2005) as cited in (Mojavezi \& Tamiz, 2012), collected data from three hundred and eighty-four general education teachers in order to scrutinize how the interaction between student and teacher characteristics affects teachers' predictions of students' academic and social success. The participants responded to one of 32 possible case studies describing a student, in which gender, reading achievement, social behavior, and attentiveness were manipulated experimentally, and to a 16 item teacher-efficacy scale. Their findings showed that 
teachers with high efficacy made less negative predictions about students, and appeared to change their predictions when student characteristics changed, while low efficacy teachers appeared to be diverting attention to a single characteristic when making their predictions. Also, all teachers reacted similarly to students who showed a combination of aggressive and inattentive behaviors, that is, if students were friendly, inattentiveness were tolerated more than if they were aggressive. Furthermore, all teachers made higher predictions of academic success for students reading on grade level even when they were aggressive, than for students reading below grade level even when they were friendly.

Pappamihiel, Ousley-Exum and Ritzhaupt (2017) conducted a study to investigate the beliefs of pre-service teachers regarding dominant language learners (DLLs), pre-service teachers' perspectives on language, and beliefs about their preparedness to teach DLLs. In this study, pre- service teacher participants viewed digital stories created by DLLs in grades K-12 to see what kind of effect, if any, these stories had on their attitudes. Collecting both quantitative and qualitative data, it was found that the stories did, in fact, have an influence on pre-service teachers' attitudes, including those related to perspectives on language and their sense of self-efficacy in teaching DLLs. Among the findings was indirect contact with DLLs can influence pre-service teachers' beliefs and attitudes. Through both quantitative and qualitative analyses, the authors were able to see positive shifts in the way in which they reflected on their attitudes and beliefs and sense of self-efficacy in teaching DLLs. The implications of this study related directly to teacher education programs in which a stand-alone course that prepares all teachers to work with DLLs is not feasible.

Mojavez and Tamiz (2014) conducted a study on the impact of teacher self-efficacy on the students' motivation and achievement. The objective of this research was to investigate the influence of teacher self-efficacy (TSE) on the students' motivation and achievement. Eighty senior high school teachers in four different cities in Iran, and one hundred and fifty senior high school students, based on their teachers' level of self-efficacy, have been selected randomly. For data collection, two instruments were employed: Teacher Self-Efficacy and Students' Motivation questionnaires. Data were analyzed through Pearson product-moment correlation coefficient and ANOVA. The results of the study revealed that teacher self-efficacy has a positive influence on the students' motivation and achievement. Findings revealed that there is a reasonably positive correlation between teacher self-efficacy and different aspects of students' motivation: However, for the correlation between teacher self-efficacy and students' extrinsic motivation the result seems interesting: the more the efficacy of the teacher, the less the extrinsic motivation of the students' will be.

Ferrell and Lim (2005) conducted a study on teachers' beliefs and classroom practices. They reported that the teachers did have a set of complex belief systems. Their beliefs were complex as sometimes they were not reflected in their classroom practice because of some factors such as time which was a constraint. Barnard and Scampton (2008) conducted a study on teacher beliefs about grammar and grammar teaching by English for Academic Purposes (EAP) teachers in New Zealand. Thirty-two teachers participated by responding to questionnaire online. Interviews were also conducted via email. The findings revealed that the teachers favoured the teaching of grammar in context. There were instances of form-focused strategies used but explicit reference to metalanguage was avoided.

Ilyana (2017) conducted a study to evaluate the rural area learners' writing self-efficacy using two different approaches which are qualitative and quantitative approach. A case study design was employed where three form four students and a teacher were involved in the research for six months. The learners' writing self-efficacy was investigated using a combination of quantitative (writing self-efficacy scale adapted from Bottomley, Henk, \& Melnick, 1997) and qualitative (classroom observation). Classroom observation was based on three characteristics: persistence in accomplishing language tasks, self-awareness of English proficiency, and willingness to engage in language activities. These characteristics which were used by Wang and Pape (2007) were based on Bandura's (1997) concept of self-efficacy. Overall, this study did not focus on the score of WSE scales alone but also placed a heavy emphasis on the perceptions and actions of the form four students and teacher. This was done through 15 non-participant classroom observations, 10 interviews with each of the three students and 10 teacher's interviews to understand the participants' self-efficacy phenomena in their learning to write. Findings showed that the combination of different method of collecting data for writing self-efficacy was a feasible way in explaining rural learners' writing self-efficacy development.

Teacher's self-efficacy beliefs may have an impact on student's achievement in several ways: teachers who possess high self-efficacy beliefs are more likely than teachers with a low sense of self-efficacy to implement informative innovations in the classroom, to employ classroom management approaches and sufficient teaching methods and promote students' autonomy, and to take charge for students with special learning needs (Allinder, 1994), to administer classroom problems (Chacon, 2005), and to provide and maintain students undertaking task (Podell \& 
Soodak, 1993).

\subsection{Theoretical Framework}

According to Rotter's (1996) Social Learning Theory, teachers believe that factors under their control have an impact on the results of their teaching. This is in line with Bandura's opinion that "people regulate their level and distribution of effort in accordance with the effects they expect their actions to have" (Bandura, 1986, p. 129). Bandura's social learning theory indicates that self-efficacy beliefs thought patterns and emotions that enable them to pursue their goals in spite of obstacles (Bandura, 1997). Another theory that influences the conceptions in this study is Carl Roger's Facilitation theory (1961). This theory is based on the humanistic approach which emphasises student-centred teaching. The facilitation is provided by the teacher who does it through his or her attitude in his or her personal relationship with the students (Rogers, 1961). This relationship takes place when the teacher guides the students as they perform a task.

\section{Methodology}

A case study research design was employed in this study. The case was teacher teaching a particular class in a particular school. The research was conducted in one Islamic Religious school in Perak. The sample selection was purposive, that is, a teacher teaching a class of students whose English language proficiency was very low. It was intended in the research to conduct an in-depth study of such a case so that the steps can be taken to alleviate the condition.

\subsection{Classroom Observation}

According to Angrosino (2007) observation is often used when the researchers tried to investigate the norms, values and meanings in a subject under the investigation. Observation is not limited to the process of recording data from the environment but the researchers should actively observe, listen and organise data so that the data obtained will have meaning and significance to the investigation. Observations were made over a period of ten lessons. Non-participant observation was conducted when the teacher was teaching. The objective was to obtain information regarding her teaching procedures that would enable the researcher to record how the teacher's beliefs and efficacy helped the shape the teacher's instructional strategies.

\subsection{Interview}

Interview is a method of data collection involving the researcher asking questions to get the answers or responses from the participants. According to Creswell (2007), the "ice breaking session" is very important to build a good rapport and to begin the interview, and the use of open-ended questions will allow maximum responses from the participants. Probing the questions by the researchers to get more clarification and elaboration about certain issues will lead to answering and responding the questions. An interview with the English teacher was conducted at the beginning of the research study. The objective was to obtain information regarding the students she had and her pedagogical practices. She was informed the number of observations that will be conducted in her class.

\subsection{Data Analysis}

Data obtained from observations of classroom teaching were recorded in descriptive terms. A description of how the teacher started each lesson and developed it was written down. The steps in the teaching process taken by the teacher in each lesson were compared to discover the similarities and differences. The recorded interview was carefully transcribed to extract excerpts which were relevant to the research. The transcripts were read and important points were marked. The main points referred to the teacher's beliefs, efficacy and how the teacher helped the students in improving their language proficiency.

\section{Findings}

The findings of the study are based on the research question formulated. They pertain to the teacher's beliefs and efficacy about her own teaching.

What are the teacher's beliefs and efficacy about her own teaching?

The answer to this question was obtained through an interview with the teacher and the observations made in the classroom.

\subsection{Findings from the Classroom Observations}

1). The teacher in this study has several beliefs regarding her own teaching.

The students could write well if they were closely guided. This is reflected in her teaching. The observations showed the teacher firstly explained the topic of the composition the students had to do. She asked the students questions regarding the topic to get ideas from them. She also gave them clues to stimulate their thinking. 


\section{Excerpt 1.}

Teacher: After a rain what do you have?

Student: Flood.

Teacher: Have you ever experienced flood?

Student: Yes.

Teacher: What happened when there is flows? ... Water rises.

Student: Barang-barang hilang. (Lost of things)

: Barang-barang hanyut. (Things washed away by water)

Teacher: What is hanyut? (What is drift?)

Student: (Studenrs refer to the dictionary)

: Drift (Wash away)

Teacher: Which one is a suitable meaning?

Student: Wash away

Teacher: Carried way. You lose your belongings. What else?

2). The teacher should teach slowly using appropriate strategies according to the students' level of proficiency. The teacher was able to adjust her pace of teaching according to the needs of the students. When the students were not familiar with the topics, the teacher made sure that they understood the vocabulary items they had to use in the composition. She also checked the students' understanding of the task they had to perform.

\section{Excerpt 2.}

Teacher: (Reads instruction of a task students had to do.)

Your school invited Dr. Mohd Fikri, a counsellor, to give a talk on social problems of teenagers. Read the talk and then complete the diagram with suitable word or phrases.

OK. What do you do? What is the social problem you find in the text?

OK. Come and write in front. (Teacher selects students)

Students: (Students write on the blackboard)

Smoking, cut classes, illegal racing, play truant, drunk driving, alcoholism.

The excerpt shows evidence of the teacher checking the students' understanding of the text they had read. As they read the text, the teacher helped them out with the vocabulary items. When a student could not understand what a certain word meant, the teacher often provided the meaning in Malay. This was to ensure that the student understood the meaning directly and easily.

\section{Excerpt 3.}

Teacher: Anything you can't understand?

Student: Apa makna dependent? (what is the meaning of dependent?)

Teacher: Maknanya you bergantung kepada orang lain. (It means you are dependent on others).

3). Using the translation method would help students to understand new or difficult words.

Excerpt 4.

Teacher: What is the conversation about?

Student: Bully.

Teacher: Any word you don't understand?

Students: Assembly.

Teacher: Perhimpunan. (Assembly)

4). Focus on grammar was necessary so that the students could write grammatically correct sentences. Grammar was dealt more implicitly than explicitly. In one lesson the teacher guided the students to write a speech by checking what they had to do. The teacher explained what they had to include in a talk. 


\section{Excerpt 5.}

Teacher: Introduce yourself. Say where you come from. Tell the

audience 'I am standing here to talk about...

Then you start.

Another instance was when the teacher corrected the tense in a student's answer.

Excerpt 6.

Teacher: Now go to question three. Why was Aminah sad?

Student: Aminah is sad...

Teacher: was sad

Student: Aminah was sad...

5). Providing feedback would improve the students' writing.

Verbal feedback was given during lessons when the students provided correct answers to the questions given. The verbal form was often an expression such as 'OK', 'Good' or a repetition of the students' answer. Feedback was also given when the teacher corrected the students' written work. The teacher wrote the word 'good' when the work was well done. She also corrected errors made by the students. She wrote notes for them to see her when the work was badly done so that she could provide them additional guidance.

6). Weak students should be given more attention and guidance.

In the case of the students in this all of them were considered weak. Two of them in particular were very weak. The teacher made them sit in front row so that she could monitor their progress easily.

\subsection{Findings from the Teacher's Interview}

\subsubsection{The Teacher's Efficacy}

In the interview with her, she described her group of students as one of mixed abilities, ranging from the " $\mathrm{B}$ " students to the "E" students. The very weak ones could neither read in English nor in Malay, their mother tongue. The students were in Form Three, the year when they would be sitting for their Lower Secondary Examination, an important standardised national examination, at the end of that year. The teacher stated that the students' awareness of the significance of the examination had helped to improve their attitude towards the English Language subject, which was compulsory for them to take. Her main objective was to prepare the students to sit for this examination. For writing skills, the teacher was clear about what skills the students needed in order to be able to write the different types of composition specified in the Curriculum for Form Three students and on which they would be tested in the Lower Secondary Examination. She also recognised that different students needed help in different ways. She planned and implemented her classroom practices for teaching writing to help her students to learn these skills with some success. During the interview, she spoke with a distinctly resigned tone about her and her colleagues' efforts in teaching their respective subjects which were met with what they perceived as a sluggish attitude by the students. Despite seemingly discouraging situation that she was faced with, the teacher was observed to have conducted her class in an unaffected and normal manner. This could be an indication of her strong sense of responsibility towards her students and also her sense of self-efficacy in helping her students to develop the language skills required of them.

The main factor that contributed to the teacher's teaching of writing was the teacher herself. Her experience in teaching the English language to weak learners had enabled her to use certain instructional strategies. She knew what the students were weak at and how weak they were. She had believed in explaining the task to be done at the beginning of the lesson and identifying new vocabulary items related to the topic. The meanings of the new words were not given to the students. Instead, the teacher gave clues for the students to guess the meanings on certain occasions. At other times she allowed the students to use the dictionary (bilingual or trilingual dictionary). None of the students used the monolingual English dictionary. The students' reliance on the dictionary indicated the need to include contextual clues in the modules. This strategy would teach the students how to obtain meanings of words by reading the linguistic as well as visual clues given.

\subsection{The Teacher's Beliefs}

The teacher's beliefs of her students' capabilities and their language needed help shape the teacher's instructional strategies. She felt they had to be guided all the way. Some of them were not able to write a single sentence in English. Some were able to write sentences but they were not grammatically correct. Their linguistic needs were 
not grammar alone but also semantics. Their lack of knowledge of vocabulary items hampered their writing as they were not able to use the appropriate words in their compositions. When words were given they were not able to use them without understanding what they meant. Based on the information obtained, activities that guided the students to construct grammatically correct sentences were included.

\subsection{Discussion and Conclusion}

Research on teachers' belief systems suggests that they are derived from a number of different sources (Kindsvatter, Willen, \& Isher, 1988). These include their own experience as language learners, experience of what works best, established practice, personality factors, educationally based or research-based principles and principles derived from an approach or method.

The teacher has a number of beliefs about her own teaching. Her beliefs were reflected in her teaching. Being an experienced teacher she believed in providing ample guidance to enable the weak students to write compositions in English. Teaching weak learners of English was time-consuming as she to keep pace with the students' progress. She had to tolerate their slow development in mastering the language. Furthermore, she had to exercise a lot of patience in ensuring that they understood the texts they read and the exercises they did. Based on observation of the teacher's performance and the interview, the teacher's increased sense of efficacy can be related to mastery experience. The findings of this study is in line with the findings reported by Richards, Gallo, and Renandya (2001) in the study of teachers' beliefs, where by the found that Hong Kong teachers of English believed their primary role in the classroom was to: (1) provide useful learning experiences, (2) provide a model of correct language use, (3) answer learners' questions, and (4) correct learners' errors. They believed their main role as an English teacher was to (1) help students discover effective approaches on learning, (2) pass on knowledge and skills to pupils, and (3) adapt teaching approaches to match their students' needs. The kind of learners they felt did best in their classes were: (1) those who were motivated, (2) those who were active and spoke out, (3) those who were not afraid of making mistakes, and (4) those who could work individually without the teacher's help.

In Bandura's (1993, p. 118) words, "efficacy beliefs influence how people feel, think, motivate themselves and behave". These beliefs play a significant role in human functioning (Bandura, 1989, 2002). In education, teacher self-efficacy has been positively related to the quality of their teaching practices (Tschannen-Moran \& Hoy, 2001; Ruble, Usher, \& McGrew, 2011).

In the study, the teacher claimed that her students either improved in their writing skills or they maintained the level they were at, but never regressed to a lower level of proficiency. Her interpretation of her students' performance, especially, that which showed improvement, assured her that her instructional strategies applied were capable of helping students. This assurance in turn seemed to enhance her beliefs in her own capabilities to make learning happen in her classroom. Evidence of the effect of the instructional strategies in enhancing the teacher's efficacy was found in her explanation of how reading her students' work and the questions that they asked in class helped her to improve 'her teaching', ways of teaching, self-esteem and ways of speaking'. Bandura (1993) stated that it requires a strong sense of efficacy to remain task oriented when faced with challenges. The stronger a person's belief is in his or her own capabilities, the greater and more persistent are their efforts (Bandura, 1989). The many years of teaching experience an English teacher in state school and the faith school in which the study took place could have given the teacher the confidence in her teaching abilities, hence her unaffected behaviour in the classroom observed. Bandura (1997) in Ruble, Usher and McGrew (2011) proposed mastery experience as a source of self-efficacy. The teacher's perception that the students' weaknesses were due to their "lazy" and uncaring attitude rather than a lack of knowledge of how to do a language learning task could also have given her reason to believe that the students were teachable and had the knowledge to perform the learning tasks and produce the outcomes set for them. Wolters and Daugherty (2007) reported that experienced teachers were more confident in their abilities to teach and manage their classrooms in ways that would even be beneficial to the most difficult-to-reach students.

Certain studies have shown the effects of the teacher's beliefs on the students' performance. They compared the teacher's beliefs and the teachers' behaviour in the classroom (Johnson, 1992; Woods, 1996; Smith, 1996). This study not only compared the teacher's belief and her subsequent performance in the classroom, it also described the process and procedures executed by the teacher based on her beliefs. The observations and the interviews conducted in this study enabled the researchers to discover how the teacher's practices were influenced by her beliefs and efficacy.

The improvement in her teaching, self-esteem, and ways of speaking indicated an increased sense of confidence, in other words, an enhancement of teacher efficacy. This enhanced efficacy enabled her to try something new in 
class, especially, she said, when things did not go according to plan or she simply did not know what to do for a teaching task. Her willingness to try something new despite not being sure whether it could work or not with her students implied that she has a strong sense of efficacy. Teacher's beliefs and self-efficacy about their capabilities to educate students will influence their decisions on the types of experiences they construct for students. These educational learning experiences play an important role in students' academic decision making towards a goal. The study implicates that understanding the sources of a teacher's belief and self-efficacy could contribute to students' empowerment towards writing and learning English Language.

\section{Acknowledgments}

We would like to thank the Ministry of Higher Education of Malaysia for providing the fund to conduct this piece of research.

\section{References}

Allinder, R. M. (1994). The relationships between efficacy and the instructional practices of Special education teachers and consultants. Teacher Education and Special Education, 17, 86-95. https://doi.org/10.1177/088840649401700203

Bandura, A. (1986). Social foundations of thought and action: A social cognitive theory. Englewood Cliffs, NJ: Prentice-Hall.

Bandura, A. (1989). Human agency in social cognitive theory, American Psychologist, 44(9), 1175-1184. https://doi.org/10.1037/0003-066X.44.9.1175

Bandura, A. (1993). Perceived self-efficacy in cognitive development and functioning. Educational Psychologist, 28(2), 117-148. https://doi.org/10.1207/s15326985ep2802_3

Bandura, A. (1997). Self-efficacy: The exercise of control. New York: W. H. Freeman andCompany.

Bandura, A. (2002). Social cognitive theory in cultural context. Applied Psychology: An International Review, 51(2), 1-26. https://doi.org/10.1111/1464-0597.00092

Berman, P., McLaughlin, M., Bass, G., Pauly, E., \& Zellman, G. (1977). Federal Programs supporting educational change. Vol. VII Factors affecting implementation and continuation. Santa Monica, CA: The Rand Corporation (ERIC Document Reproduction Service No. 140432).

Borg, S. (2003). Teacher cognition in language teaching: A review of research on what language teachers think, know, believe and do. Language Learning, 36, 81-109. https://doi.org/10.1017/S02614444803001903

Burns, A. (1992). Teacher beliefs and their influence on classroom practice. Prospect, 7(3), 55-65.

Chacon, C. (2005). Teachers' perceived efficacy among English as a foreign language teachers in Venezuela. Teaching and Teacher Education, 21, 257-272. https://doi.org/10.1016/j.tate.2005.01.001

Creswell, J. W. (2007). Qualitative inquiry and research design: Choosing among five traditions (2nd Ed). Thousand Oaks, CA: Sage

Crystal, D. (1997). English as a global language. Cambridge: Cambridge University Press.

Crystal, D. (2003). English as a global language. Cambridge: Cambridge University Press. https://doi.org/10.1017/CBO9780511486999

Ferrell, T. S. C., \& Lim, P. C. P. (2005). Conceptions of grammar teaching: A case study of Teachers' beliefs and classroom practices.

Gibson, S., \& Dembo, M. (1984). Teacher efficacy: A construct validation. Journal of Educational Psychology, 76, 569-582. https://doi.org/10.1037/0022-0663.76.4.569

Guskey, T., \& Passaro, P. (1994). Teacher efficacy: A study of construct dimensions. Amrican Educational Research Journal, 31, 627-643. https://doi.org/10.3102/00028312031003627

Ilyana, A. Qualitative and Quantitative Approach in Evaluating Writing Self-Efficacy. International Journal for Innovation Education and Research, 2(7). 26-36.

Johnson, K. (1992). The relationship between teachers' beliefs and practice during literacy Instruction for non-native speakers of English. Journal of Reading Behaviour, 24(1), 83-108. https://doi.org/10.1080/10862969209547763

Kindsvatter, R., Willen, W., \& Ishler, M. (1988). Dynamics of effective teaching. New York: Longman.

Kurz, N., A. W., \& Hoy, W. K. (2007). Predictors of academic optimism: teachers' Instructional beliefs and 
professional commitment. Retrieved from http://www.coe.ohio.-state.edu/ahoy/currentresearch.htm. on 28 June 2017

Muijs, R. D., \& Rejnolds, D. (2001). Teachers' beliefs and behaviors: What really matters. Journal of Classroom Interaction, 37, 3-15.

Mojavez, A., \& Tamiz, M. P. (2012). The Impact of Teacher Self-efficacy on the Students' Motivation and Achievement. Theory and Practice in Language Studies, 2(3), 483-491. https://doi.org/10.4304/tpls.2.3.483-491

Nespor, N. (1987). The role of beliefs in the practice of teaching. Journal of Curriculum Studies, 19(4), 318-328. https://doi.org/10.1080/0022027870190403

Pajares, M. (1992). Teachers' beliefs and educational research. Cleaning up a messy Construct. Review of Educational Research, 3, 307-332. https://doi.org/10.3102/00346543062003307

Pappamihiel, N. E., Ousley-Exum, D., \& Ritzhaupt, A, (2017). The impact of digital stories on preservice teacher beliefs about English language learners. Teaching and Teacher Education, 67, 171-178. https://doi.org/10.1016/j.tate.2017.06.014

Podell, D., \& Soodak, L. (1993). Teacher efficacy and bias in special education referrals. Journal of Educational Research, 86, 247-253. https://doi.org/10.1080/00220671.1993.9941836

Poor English impedes lessons. (2006, December 10). Education. The Star Online.

Raimes, A. (1983). Techniques in teaching writing. New York: Oxford University Press.

Richards, J. C., Gallo, P. B., \& Renandya, W. A. (2001). Exploring teachers' beliefs and the process of change. PAC Journal, 1(1), 41-58.

Ross, J. A. (1992). Teacher efficacy and the effect of coaching on student motivation. Canadian Journal of Education, 17, 185-190. https://doi.org/10.2307/1495395

Rotter, J. B. (1966). Generalized expectancies for internal versus external control of reinforcement. Psychological Monographs, 80. (Whole No. 609). https://doi.org/10.1037/h0092976

Ruble, L. A., Usher, L. U., \& McGrew, J. H. (2011). Preliminary investigation of the sources of self-efficacy among teachers of students with autism. Focus on Autism and Other Developmental Disabilities, 26(2), 67-74. https://doi.org/10.1177/1088357610397345

Shavelson, R. J., \& Stern, P. (1981). Research on teachers' pedagogical thoughts, judgments, Decisions, and behaviour. Review of Educational Research, 51, 387-402. https://doi.org/10.3102/00346543051004455

Smith, J. P. (1996). Efficacy and teaching mathematics by telling: A challenge for reform. Journal for Research in Mathematics Education, 27, 387-402. https://doi.org/10.2307/749874

Tschannen-Moran, M., \& Hoy, A. W. (2001). Teacher efficacy: capturing an elusive construct. Teaching and Teacher Education, 17, 783-805. https://doi.org/10.1016/S0742-051X(01)00036-1

Tillema, H. H. (2000). Belief change towards self-directed learning in student teachers: immersion in practice or reflection on action. Teaching and Teacher Education, 16, 575-591. https://doi.org/10.1016/S0742-051X(00)00016-0

Tunku Mohani, T. M., Charanjit Kaur Swaran Singh, Nadiah, Y. A., \& Mazyani, M. (2015). Developing the speaking skill among ESL elementary learners. The Asian Journal of English Language And Pedagogy, $3(3)$.

Wolters, C. A., \& Daugherty, S. G. (2007). Goal structures and teachers' sense of efficacy. Their Relation and association to teaching experience and academic level. Journal of Educational Psychology, 99(1), 181-193. https://doi.org/10.1037/0022-0663.99.1.181

Woods, D. (1996). Teacher cognition in language teaching. Cambridge: Cambridge University Press.

\section{Copyrights}

Copyright for this article is retained by the author(s), with first publication rights granted to the journal.

This is an open-access article distributed under the terms and conditions of the Creative Commons Attribution license (http://creativecommons.org/licenses/by/4.0/). 